Interactions between the Tetrasodium Salts of EDTA and 1-Hydroxyethane 1,1-Diphosphonic Acid with Sodium Hypochlorite Irrigants

Biel, Philippe ; Mohn, Dirk ; Attin, Thomas ; Zehnder, Matthias

DOI: https://doi.org/10.1016/j.joen.2016.12.006

Posted at the Zurich Open Repository and Archive, University of Zurich ZORA URL: https://doi.org/10.5167/uzh-141337

Journal Article

Accepted Version

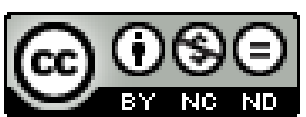

The following work is licensed under a Creative Commons: Attribution-NonCommercial-NoDerivatives 4.0 International (CC BY-NC-ND 4.0) License.

Originally published at:

Biel, Philippe; Mohn, Dirk; Attin, Thomas; Zehnder, Matthias (2017). Interactions between the Tetrasodium Salts of EDTA and 1-Hydroxyethane 1,1-Diphosphonic Acid with Sodium Hypochlorite Irrigants. Journal of Endodontics, 43(4):657-661.

DOI: https://doi.org/10.1016/j.joen.2016.12.006 


\section{Interactions between the Tetrasodium Salts of EDTA and HEDP with Sodium Hypochlorite Irrigants}

Philippe Biel, MDS, ${ }^{1}$ Dirk Mohn, PhD, ${ }^{1,2}$ Thomas Attin, Prof. Dr. med. dent., ${ }^{1}$ and Matthias Zehnder, Dr. med. dent. $\mathrm{PhD}^{1}$

${ }^{1}$ Clinic of Preventive Dentistry, Periodontology and Cariology, University of Zurich, Center of Dental Medicine, Switzerland

${ }^{2}$ Institute for Chemical and Bioengineering, Department of Chemistry and Applied Biosciences, ETH Zurich, Switzerland

Key words: sodium hypochlorite; NaOCl; HEDP; etidronate; HEBP; EDTA

Correspondence:

Dr. Matthias Zehnder

Division of Endodontics

Clinic of Preventive Dentistry, Periodontology and Cariology

University of Zurich, Center of Dental Medicine

Plattenstrasse 11, CH-8032 Zurich

Switzerland

Phone: $\quad+41446343284$

FAX: $\quad+41446344308$

E-mail_matthias.zehnder@zzm.uzh.ch 


\begin{abstract}
Introduction: A clinically useful all-in-one endodontic irrigant with combined proteolytic and decalcifying properties is still elusive. In this study, the chemical effects of dissolving the tetrasodium salts of 1-hydroxyethane 1,1-diphosphonic acid ( $\mathrm{Na}_{4} \mathrm{HEDP}$ ) or ethylenediaminetetraacetic acid $\left(\mathrm{Na}_{4}\right.$ EDTA) directly in sodium hypochlorite $(\mathrm{NaOCl})$ irrigants in polypropylene syringes were assessed over the course of $1 \mathrm{~h}$. Methods: The solubility of the salts in water was determined. Their compatibility with $1 \%$ and $5 \% \mathrm{NaOCl}$ was measured by iodometric titration, and in a calcium complexation experiment using a $\mathrm{Ca}^{2+}$-selective electrode. Results: The salts dissolved within 1 min. The dissolution maximum of $\mathrm{Na}_{4} \mathrm{HEDP}$ in water (wt/total wt) was $44.6 \pm 1.6 \%$. The corresponding dissolution maximum of $\mathrm{Na}_{4}$ EDTA was $38.2 \pm$ $0.8 \%$. $\mathrm{Na}_{4} \mathrm{HEDP}$ at $18 \%$ in $5 \% \mathrm{NaOCl}$ caused a mere loss of $16 \%$ of the initially available chlorine over $1 \mathrm{~h}$. In contrast, a corresponding mixture between $\mathrm{NaOCl}$ and the $\mathrm{Na}_{4} \mathrm{EDTA}$ salt caused $95 \%$ reduction in available chlorine after 1 min. Mixtures of $3 \% \mathrm{Na}_{4}$ EDTA with $1 \%$ $\mathrm{NaOCl}$ were more stable, but only for $30 \mathrm{~min}$. The $\mathrm{Na}_{4} \mathrm{HEDP}$ lost $24 \%$ of its calcium complexation capacity after $60 \mathrm{~min}$. The corresponding loss for $\mathrm{Na}_{4} \mathrm{EDTA}$ was $34 \%$. Conclusions: The compatibility and solubility of particulate $\mathrm{Na}_{4} \mathrm{HEDP}$ with/in $\mathrm{NaOCl}$ solutions is such that these components can be mixed and used for up to $1 \mathrm{~h}$. In contrast, short-term compatibility of the $\mathrm{Na}_{4}$ EDTA salt with $\mathrm{NaOCl}$ solutions was considerably lower, decreasing at higher concentrations of either compound. Especially for $\mathrm{Na}_{4} \mathrm{HEDP}$, but also for $\mathrm{Na}_{4} \mathrm{EDTA}$, the $\mathrm{NaOCl}$ had little effect on calcium complexation.
\end{abstract}


The term chemomechanical root canal preparation relates to the clinical concept of cleaning infected and/or inflamed root canal systems by means of instrumentation and irrigation with a chemically active substance. The goal is to clean the canal system and condition the canal wall for a subsequent filling procedure. Current approaches aim to remove the inflamed or necrotic soft tissue, smear layer, and biofilm, if present. Subsequently, the canal wall can be conditioned to improve the attachment of alloplastic filling materials (1), or to release growth factors to engineer a pulp-like tissue (2).

Alkaline sodium hypochlorite $(\mathrm{NaOCl})$ solutions are the most widely used endodontic irrigants $(3$, 4). These $\mathrm{NaOCl}$ solutions are relatively cheap and readily available from various commercial sources (5). Furthermore, $\mathrm{NaOCl}$ solutions feature unique soft tissue and biofilm matrix dissolution properties $(6,7)$. However, irrigation with $\mathrm{NaOCl}$ solutions has no effect on the inorganic aspects of the smear layer (8), and does not prevent the accumulation of inorganic debris during instrumentation (9). Consequently, irrigation protocols using sodium hypochlorite in an alternating mode with an aqueous solution containing a decalcifying agent such as EDTA or citric acid have been proposed (10). However, these protocols are not necessarily user-friendly. Because of the chemical reactivity of $\mathrm{OCl}^{-}$(hypochlorite) with most decalcifying agents, especially those in acidic form, combined use is not possible $(11,12)$. The search for hypochlorite-compatible decalcifying agents or chelators in endodontic research has yielded two candidates thus far: tetrasodium $\operatorname{HEDP}\left(\mathrm{Na}_{4} \operatorname{HEDP}\right)(12,13)$ and tetrasodium EDTA $\left(\mathrm{Na}_{4}\right.$ EDTA $)(14,15)$. Both, 1-hydroxyethane 1,1-diphosphonic acid (HEDP or etidronate) and ethylenediaminetetraacetic acid (EDTA) are available as disodium and tetrasodium salts, depending on the desired $\mathrm{pH}$. These biocompatible chelators are commonly used in the cosmetic, food and dish washing, and the laundry detergent industry (16). HEDP has a higher calcium binding capacity per gram chelator (16), while EDTA has a stronger affinity to calcium, i.e. a higher dissociation constant of the complex (17). Consequently, EDTA has a higher demineralizing effect than HEDP, and can erode dentin (18). EDTA solutions of a concentration lower than the usual 17\% have thus been proposed. It has been shown that 3\% EDTA can remove smear layer as effectively as 24\% EDTA (19). It would appear that the reduction of the available chlorine that occurs in direct mixtures with $\mathrm{Na}_{4} \mathrm{HEDP}$ is less than that in counterparts containing $\mathrm{Na}_{4}$ EDTA $(12,15)$. However, a direct comparison is elusive. Furthermore, it is not known how 
the calcium binding capacity (complexation) of these two chelators is affected by the presence of $\mathrm{NaOCl}$ in aqueous mixtures.

It is known from previous research that no chelator investigated thus far has true long-term compatibility with $\mathrm{NaOCl}$ (12). Consequently, it was the goal of the present investigation to study short-term chemical interactions between the tetrasodium salts of HEDP and EDTA with $\mathrm{NaOCl}$ irrigants at different concentrations recommended by previous research. To simulate a clinical scenario, mixtures were made directly in 10-mL polypropylene irrigation syringes.

\section{Materials and Methods}

\section{Particles and Solutions}

The tetrasodium salts of 1-hydroxyethane 1,1-diphosphonic acid (HEDP) and ethylenediaminetetraacetic acid (EDTA) were obtained from commercial sources (HEDP: Cublen K8514GR, Zschimmer \& Schwarz, Burgstädt, Germany, batch no. 92729; EDTA: Sigma Aldrich, Steinheim, Germany, batch no. 058K0136). The salts were sieved through a stack of precision sieves with defined screen openings (Test Sieve, Retsch GmbH, Haan, Germany). Particles from the 300 to $500-\mu \mathrm{m}$ fraction were used for all subsequent experiments.

The solutions used in these experiments were 5.0\% and $1.0 \% \mathrm{NaOCl}$. They were diluted from a concentrated $14 \%$ stock solution using pure reagent-grade water. The stock solution was kept at $5^{\circ} \mathrm{C}$ in an amber glass bottle. Diluted solutions were prepared freshly before each experiment (see below) and warmed to ambient temperature. Available chlorine was determined and verified using iodometric titration (20).

\section{Dissolution maximum}

The particles were dissolved in $25 \mathrm{~mL}$ of deionized water at room temperature. The powders were incrementally added under constant stirring until the particles stopped to dissolve. This procedure was repeated twice per chelator salt under investigation (triplicate experiments). Subsequently, the solutions were filtered using a .22- $\mu \mathrm{m}$ syringe filter (TPP Techno Plastic Products AG, Trasadingen, Switzerland). To determine the weight of the dissolved salts per total weight of solution, $5 \mathrm{~mL}$ of the filtered solutions were pipetted into a pre-weighed glass vial. Weights were determined using a precision balance (Mettler AT261 DeltaRange, Mettler Toledo Int. Inc., Columbus, OH). Subsequently, the probes were desiccated in a drying oven (HORO 
type $038 \mathrm{~A}$, Dr. Ing. A. Hoffmann, Ostfildern, Germany) at $120^{\circ} \mathrm{C}$ until all the water had evaporated and a steady weight was achieved.

\section{Effect of chelator salts on available chlorine}

In this experiment, the chelator salts were added to and dissolved in pre-weighed amounts of $1 \%$ or $5 \% \mathrm{NaOCl}$. The mixtures were prepared directly in $10-\mathrm{mL}$ polypropylene syringes (Omnifix REF4617100V, B.Braun, Melsungen, Germany). The plungers were removed and the syringe openings closed using paraffin film (Parafilm, Bemis, Neenah, WI). The $\mathrm{NaOCl}$ solution and the chelator salt were added and the syringe hubs were closed using Parafilm (Bemis). Experiments were performed in triplicates at the intervals and concentration measured, i.e. three separate syringes were prepared each (total of 150 syringes for these experiments, see Tables 1 and 2). Experiments were performed at ambient temperature. The triplicate samples per concentration/time were placed in a centrifuge tube rack and gently shaken by hand for $1 \mathrm{~min}$. By that time, the chelator salts had dissolved completely. Aliquots of the mixed solutions, approximately $0.5 \mathrm{~g}$, were weighed in the precision balance. They were removed after 1, 10, 20, 30 , and $60 \mathrm{~min}$ and assessed for their amount of available chlorine using a titration apparatus (665 Dosimat, Deutsche Metrohm GmbH \& Co. KG, Filderstadt, Germany). A 0.1 mol/L sodium thiosulfate solution (Merck KGaA Darmstadt, Darmstadt, Germany, Lot. no. HC378976) was used as titrator. In addition, the temperature and the $\mathrm{pH}$ of the reaction mixtures were recorded. Temperature measurements were performed using an electronic thermometer (Checktemp 1, Hanna Instruments, Leighton Buzzard, Great Britain) and $\mathrm{pH}$ measurements using a calibrated microelectrode (827 pH lab, Deutsche Metrohm GmbH \& Co. KG).

\section{Effect of hypochlorite on $\mathrm{Ca}^{2+}$ complexing capacity}

To study the effect of the interactions between the hypochlorite and the chelators under investigation, the salts were added to a $5 \% \mathrm{NaOCl}$ solution. (From the available chlorine experiment), it was expected that there was more interaction in this solution than in the $1 \%$ counterpart. Again, mixtures were prepared in individual syringes in triplicates for each time point and combination as described above (36 syringes in total, see Table 3 ). To stop the reaction, $0.6 \mathrm{~g}$ sodium thiosulfate was added to the mix immediately, after 30 or $60 \mathrm{~min}$. To determine the

$\mathrm{Ca}^{2+}$ complexing capacity of the two chelators in the presence of $\mathrm{NaOCl}$, a calcium chloride standard solution $\left(\mathrm{CaCl}_{2} * 2 \mathrm{H}_{2} \mathrm{O}, 18.35 \mathrm{~g} / 5 \mathrm{~L}\right.$, EMSURE, Merck) was used instead of the 
commonly used calcium carbonate standard. The concentration of the standard solution (1000 ppm $\mathrm{Ca}^{2+}, \mathrm{pH}$ 6.1) was verified using an atomic absorption spectrometer (contrAA 300, Analytik Jena AG, Jena, Germany) and compared to that of a commercially available $1000 \mathrm{ppm} \mathrm{Ca}^{2+}$ standard solution (CertiPUR calcium carbonate, Merck, no. 1.19778.0100). A pilot study revealed that the $\mathrm{pH}$ effects of $\mathrm{NaOCl}$ gave rise to false readings when using a calcium carbonate standard solution ( $\mathrm{pH} 1$ ), which needs to be acidic (data not shown). Thus, the experiments had to be performed in a high-pH environment. The $\mathrm{CaCl}_{2}$ solution was buffered at $\mathrm{pH} 10$ using a commercially available boric acid/ potassium chloride/ sodium hydroxide buffer ( $2 \mathrm{~mL}$ per 100 $\mathrm{mL}$ standard solution, EMSURE, Merck). For the experiment the $1000 \mathrm{ppm} \mathrm{Ca}^{2+}$ standard solution was diluted to $100 \mathrm{ppm}$. The potential of $100 \mathrm{~mL}$ of this solution was determined using a calcium-selective electrode (ORION 93 series 9300 BN, Thermo Fisher Scientific, Waltham, MA). Subsequently, $0.1 \mathrm{~mL}$ increments of the reaction mixtures were added to $100 \mathrm{~mL}$ of the 100 ppm $\mathrm{Ca}^{2+}$ standard solution. Control measurements were performed using corresponding amounts of $6 \%$ sodium thiosulfate in $5 \% \mathrm{NaOCl}$ or deionized water.

\section{Data presentation}

All the percentage (\%) values reported relate to mass, i.e. weight of chemicals per total weight of the resulting solution. The data presented are based on triplicate experiments. Mean values and standard deviations are shown. As these data represent results from chemical experiments with little variance, only descriptive statics were applied.

\section{Results}

Both the $\mathrm{Na}_{4} \mathrm{HEDP}$ and $\mathrm{Na}_{4}$ EDTA salts dissolved in the $\mathrm{NaOCl}$ solutions within 1 min.. The dissolution maximum of $\mathrm{Na}_{4} \mathrm{HEDP}$ in water (wt/ total wt) was $44.6 \pm 1.6 \%$. The corresponding dissolution maximum of $\mathrm{Na}_{4}$ EDTA was $38.2 \pm 0.8 \%$.

Both chelator salts showed some negative effects on free available chlorine when dissolved in $\mathrm{NaOCl}$ solutions (Tables 1 and 2). When $\mathrm{Na}_{4} \mathrm{HEDP}$ powder was mixed with $1 \%$ or $5 \% \mathrm{NaOCl}$, between $72 \%$ and $87 \%$ of the initially available chlorine remained in solution after $60 \mathrm{~min}$ (Table 1 and 2). The higher concentration of HEDP (18\%) caused a slightly higher loss of available chlorine than the lower concentration $(9 \%)$, while the concentration of the $\mathrm{NaOCl}$ solution had little impact (Fig. 1). In contrast, $\mathrm{Na}_{4} E D T A$ showed some strong and dose-dependent effects, 
especially in 5\% $\mathrm{NaOCl}$ (Table 2). When $18 \% \mathrm{Na}_{4}$ EDTA was present in $5 \% \mathrm{NaOCl}$, the reaction was immediate (Fig. 1), with a concurrent drop in $\mathrm{pH}$ and rise in temperature (Table 2). In the presence of $3 \% \mathrm{Na}_{4} \mathrm{EDTA}, 5 \% \mathrm{NaOCl}$ reacted in the first $10 \mathrm{~min}$, while the $1 \%$ solution retained $87 \%$ of the available chlorine in the first $30 \mathrm{~min}$ (Table 1).

The tetrasodium salt of HEDP in $5 \% \mathrm{NaOCl}$ initially lost $9 \%$ of its calcium chelating effect compared to a pure solution in water (Table 3), and 24\% after $60 \mathrm{~min}$. These losses correlated to the time course of the interaction with the available chlorine (Table 2). The corresponding immediate loss for $\mathrm{Na}_{4}$ EDTA was $13 \%$, reaching 34\% after $60 \mathrm{~min}$. Consequently, despite its apparent interaction with the hypochlorite $\left(\mathrm{OCl}^{-}\right)$, the $\mathrm{Na}_{4}$ EDTA retained its ability to chelate $\mathrm{Ca}^{2+}$ over the course of this experiment.

\section{Discussion}

The current study investigated the potential of adding particulate chelators to $\mathrm{NaOCl}$ solutions in order to generate an ad hoc all-in-one irrigant. The $\mathrm{NaOCl}$ should maintain its $\mathrm{pH}$ and available hypochlorite $\left(\mathrm{OCl}^{-}\right)$with an additional decalcifying effect over the approximate course of an endodontic treatment. This approach would circumvent the technical problems of storing and/or mixing solutions. The results showed that the tetrasodium salt of HEDP, but not necessarily that of EDTA, is suitable for this purpose, even if the EDTA concentration is kept low.

Although the current experiments were performed in a simulated clinical environment, this is a strictly chemical investigation, and no clinical measures were obtained. The chelator salts were mixed with sodium hypochlorite solutions at room temperature in polypropylene syringes. For the experiments on the effect of hypochlorite on the chelators, a $100-\mathrm{ppm} \mathrm{Ca}^{2+}$ solution was selected, because this amount of calcium corresponds to that removed from root canals during the irrigation with chelating solutions (13). It is clear from the available literature that all the effects of $\mathrm{NaOCl}$ solutions desired by the endodontist, i.e. biofilm and necrotic tissue dissolution, are related to available chlorine and $\mathrm{pH}$ in that solution (21). HEDP in aqueous solution, when freshly mixed with a $\mathrm{NaOCl}$ solution, neither impedes the antimicrobial properties of the $\mathrm{NaOCl}$ (22), nor its ability to dissolve necrotic tissue (23). A recent study also showed that this may be the case with an alkaline solution of $\mathrm{Na}_{4}$ EDTA (15). The EDTA solution normally used by dentists has a $\mathrm{pH}$ between 7 and 8.5, and is prepared by adding sodium hydroxide $(\mathrm{NaOH})$ to the disodium salt of EDTA in water. Such a solution strongly interferes with available chlorine 
(hypochlorite) in $\mathrm{NaOCl}$ solutions (24). Tartari and co-workers reported that $\mathrm{Na}_{4} \mathrm{EDTA}$, when mixed with $\mathrm{NaOCl}$, continues to remove smear layer and has little effect on tissue dissolution in the short-term. This is in seeming contrast to the current results. However, these authors mixed $5 \% \mathrm{NaOCl}$ with solutions of $10 \%$ and $20 \% \mathrm{Na}_{4}$ EDTA (resulting in $2.5 \% \mathrm{NaOCl}$ solutions), and then assessed the smear layer $(5 \mathrm{~min})$ and soft tissue dissolution $(15 \mathrm{~min})$. The focus of the current study was different: we investigated the possibility to directly mix chelator salts with $\mathrm{NaOCl}$ solutions (resulting in higher available concentrations of chelator and hypochlorite), store these mixtures for different time intervals, and then assess their efficacy. The results reported here on the loss of available chlorine in $\mathrm{NaOCl}$ solutions are comparable to those reported by other authors; their solution initially containing $2.5 \% \mathrm{NaOCl}$ and $10 \% \mathrm{Na}_{4}$ EDTA lost $51 \%$ of the available chlorine in the first hour (15). The current results show that the more available chlorine and $\mathrm{Na}_{4}$ EDTA was in the system, the stronger was the chemical interaction between these two compounds (Tables 1 and 2). This can be explained due to kinetics, as the reaction rate is increased for higher concentrations of substrates. Consequently, the tetrasodium salt of EDTA does have some compatibility with $\mathrm{NaOCl}$, but only at low concentrations and in the short term. As reported earlier, this may be useful when two solutions are freshly mixed (15). For the application intended in this study and in the clinical situation, however, the tetrasodium salt of HEDP appears much more suitable than the EDTA counterpart.

The limited interference of the $\mathrm{NaOCl}$ solutions with the $\mathrm{Ca}^{2+}$ complexation of the chelators under investigation has also been reported in earlier studies assessing mixtures of the respective solutions $(12,13,23)$. Although $\mathrm{NaOCl}$ is a strong oxidizing agent, it had little effect on calcium chelating ability. Comparing the mixture $\mathrm{HEDP} / \mathrm{H}_{2} \mathrm{O}$ to $\mathrm{HEDP} / \mathrm{NaOCl}$, the calcium chelation was slightly reduced due to the oxidized chelator, which decomposes to acetic acid. Although there is also an oxidation of EDTA, the decomposition is rather slow (25) and can yield unknown byproducts and iminoacetic acid, which can still chelate $\mathrm{Ca}^{2+}$. Hence, EDTA could possibly chelate $\mathrm{Ca}^{2+}$ but $\mathrm{NaOCl}$ is also decomposed and there is not enough available chlorine present if used in a combined solution (Tables 1 and 2).

Anytime new materials or combinations (irrigants) are used in different combinations or with different techniques, there are many questions regarding biocompatibility and efficacy that need to be addressed. This manuscript provides a first step to at least provide the feasibility for this irrigant combination. However, apart from the self-evident advantage for clinicians to use just one irrigant, it remains unclear whether the effective concentrations of chlorine and the capacity 
of a chelating agent maintained better when 1) undiluted stable individual components are used and frequently refreshed, or 2) a single component is refreshed but constantly degrading over the hour of use. Future studies should also address the compatibility of $\mathrm{Na}_{4} \mathrm{HEDP}$ with chlorhexidine, $\mathrm{Ca}(\mathrm{OH})_{2}$, as well as etching and bonding agents. The effects of temperature and ultrasonic activation on the combined irrigant should also be assessed. Furthermore, dentin conditioning using a $\mathrm{NaOCl} / \mathrm{HEDP}$ combination should be scrutinized regarding its effects on pluripotent cells/ regenerative endodontic procedures. Last but not least, clinical studies should be performed. Indeed, it is not entirely clear whether a decalcifying agent is truly necessary to improve the outcome of root canal treatment, although follow-up studies gave a hint in that direction, at least in the case of re-treatments (26).

\section{Conclusion}

The compatibility and solubility of particulate $\mathrm{Na}_{4} \mathrm{HEDP}$ with/in $\mathrm{NaOCl}$ solutions is such that these components can be mixed and used for up to $1 \mathrm{~h}$. In contrast, short-term compatibility of the $\mathrm{Na}_{4}$ EDTA salt with $\mathrm{NaOCl}$ solutions was considerably lower, decreasing at higher concentrations of either compound. Especially for $\mathrm{Na}_{4} \mathrm{HEDP}$, but also for $\mathrm{Na}_{4} \mathrm{EDTA}$, the $\mathrm{NaOCl}$ had little effect on calcium complexation. However, it needs to be cautioned that these statements are based entirely on a laboratory study model and not on actual clinical conditions.

\section{Acknowledgments}

The authors thank Mr. Sandeep Pai for his help with the English language of this text. This research did not receive any specific grant from funding agencies in the public, commercial, or not-for-profit sectors. $P B$ and TA have no conflict of interest related to the current work. DM and MZ declare a potential conflict of interest. They are both shareholders of smartodont llc, who applied for a patent related to the basic idea of using particulate $\mathrm{Na} \mathrm{H}_{4} \mathrm{HDP}$ in endodontic irrigants and in combination with calcium hydroxide (EP16184212). 


\section{References}

1. Neelakantan P, Subbarao C, Subbarao C, De-Deus G, Zehnder M. The impact of root dentine conditioning on sealing ability and push-out bond strength of an epoxy resin root canal sealer. Int Endod J 2011;44:491-8.

2. Galler K, D'Souza RN, Federlin M et al. Dentin conditioning codetermines cell fate in regenerative endodontics. J Endod 2011;37:1536-41.

3. Palmer N, Ahmed M, Grieveson B. An investigation of current endodontic practice and training needs in primary care in the North West of England. Br Dent J 2009;206:E22; discussion $584-5$.

4. Gopikrishna V, Pare S, Pradeep Kumar A, Lakshmi Narayanan L. Irrigation protocol among endodontic faculty and post-graduate students in dental colleges of India: A survey. J Conserv Dent 2013;16:394-8.

5. Frais $\mathrm{S}, \mathrm{Ng}$ Y, Gulabivala $\mathrm{K}$. Some factors affecting the concentration of available chlorine in commercial sources of sodium hypochlorite. Int Endod J 2001;34:206-15.

6. Naenni N, Thoma K, Zehnder M. Soft tissue dissolution capacity of currently used and potential endodontic irrigants. J Endod 2004;30:785-7.

7. Tawakoli P, Ragnarsson K, Rechenberg D, Mohn D, Zehnder M. Effects of endodontic irrigants on biofilm matrix polysaccharides. Int Endod J 2016; doi: 10.1111/iej.12604 [Epub ahead of print].

8. Koskinen K, Meurman J, Stenvall H. Appearance of chemically treated root canal walls in the scanning electron microscope. Scand J Dent Res 1980;88:505-12.

9. Paque F, Boessler C, Zehnder M. Accumulated hard tissue debris levels in mesial roots of mandibular molars after sequential irrigation steps. Int Endod J 2011;44:148-53.

10. Zehnder M. Root canal irrigants. J Endod 2006;32:389-98.

11. Baumgartner J, Ibay A. The chemical reactions of irrigants used for root canal debridement. J Endod 1987;13:47-51.

12. Zehnder M, Schmidlin P, Sener B, Waltimo T. Chelation in root canal therapy reconsidered. J Endod 2005;31:817-20.

13. Zehnder M, Schicht O, Sener B, Schmidlin P. Reducing surface tension in endodontic chelator solutions has no effect on their ability to remove calcium from instrumented root canals. J Endod 2005;31:590-2. 
14. O'Connell MS, Morgan L, Beeler W, Baumgartner J. A comparative study of smear layer removal using different salts of EDTA. J Endod 2000;26:739-43.

15. Tartari T, Oda D, Zancan R et al. Mixture of alkaline tetrasodium EDTA with sodium hypochlorite promotes in vitro smear layer removal and organic matter dissolution during biomechanical preparation. Int Endod J 2016: doi: 10.1111/iej.12595 [Epub ahead of print].

16. Stanga M. Sequestrants. In: Sanitation: Cleaning and Disinfection in the Food Industry. Weinheim, Germany: Wiley, 2010:83-148.

17. Stanga M. Chemistry and problems of industrial water. In: Sanitation: Cleaning and Disinfection in the Food Industry. Weinheim, Germany: Wiley, 2010:1-76.

18. De-Deus G, Zehnder M, Reis C et al. Longitudinal co-site optical microscopy study on the chelating ability of etidronate and EDTA using a comparative single-tooth model. J Endod 2008;34:71-5.

19. Daghustani M, Alhammadi A, Merdad K, Ohlin J, Erhardt F, Ahlquist M. Comparison between high concentration EDTA (24\%) and low concentration EDTA (3\%) with surfactant upon removal of smear layer after rotary instrumentation: A SEM study. Swed Dent J 2011;35:915.

20. Vogel A. A textbook of quantitative inorganic analysis. London: Longmans, 1962:363-5.

21. Aubut V, Pommel L, Verhille B et al. Biological properties of a neutralized $2.5 \%$ sodium hypochlorite solution. Oral Surg Oral Med Oral Pathol Oral Radiol Endod 2010;109:e120-5.

22. Arias-Moliz MT, Ordinola-Zapata R, Baca P, Ruiz-Linares M, Ferrer-Luque CM. Antimicrobial activity of a sodium hypochlorite/etidronic acid irrigant solution. J Endod 2014;40:1999-2002.

23. Tartari T, Guimaraes B, Amoras L, Duarte M, Silva E Souza PA, Bramante C. Etidronate causes minimal changes in the ability of sodium hypochlorite to dissolve organic matter. Int Endod J 2015;48:399-404.

24. Grawehr M, Sener B, Waltimo T, Zehnder M. Interactions of ethylenediamine tetraacetic acid with sodium hypochlorite in aqueous solutions. Int Endod J 2003;36:411-7.

25. Grande N, Plotino G, Falanga A, Pomponi M, Somma F. Interaction between EDTA and sodium hypochlorite: A nuclear magnetic resonance analysis. J Endod 2006;32:460-4.

26. Ng YL, Mann V, Gulabivala K. A prospective study of the factors affecting outcomes of nonsurgical root canal treatment: part 1: periapical health. Int Endod J 2011 Jul;44:583-609. 


\section{Caption:}

Figure 1. $\mathrm{NaOCl}$ concentrations in the 2 solutions used in this study over time, as assessed by iodometric titration. Note that $\mathrm{Na}_{4}$ EDTA salt caused a faster decline in available chlorine in the $5 \%$ compared to the $1 \% \mathrm{NaOCl}$ solution. This was not the case with the $\mathrm{Na}_{4} \mathrm{HEDP}$ salt. 


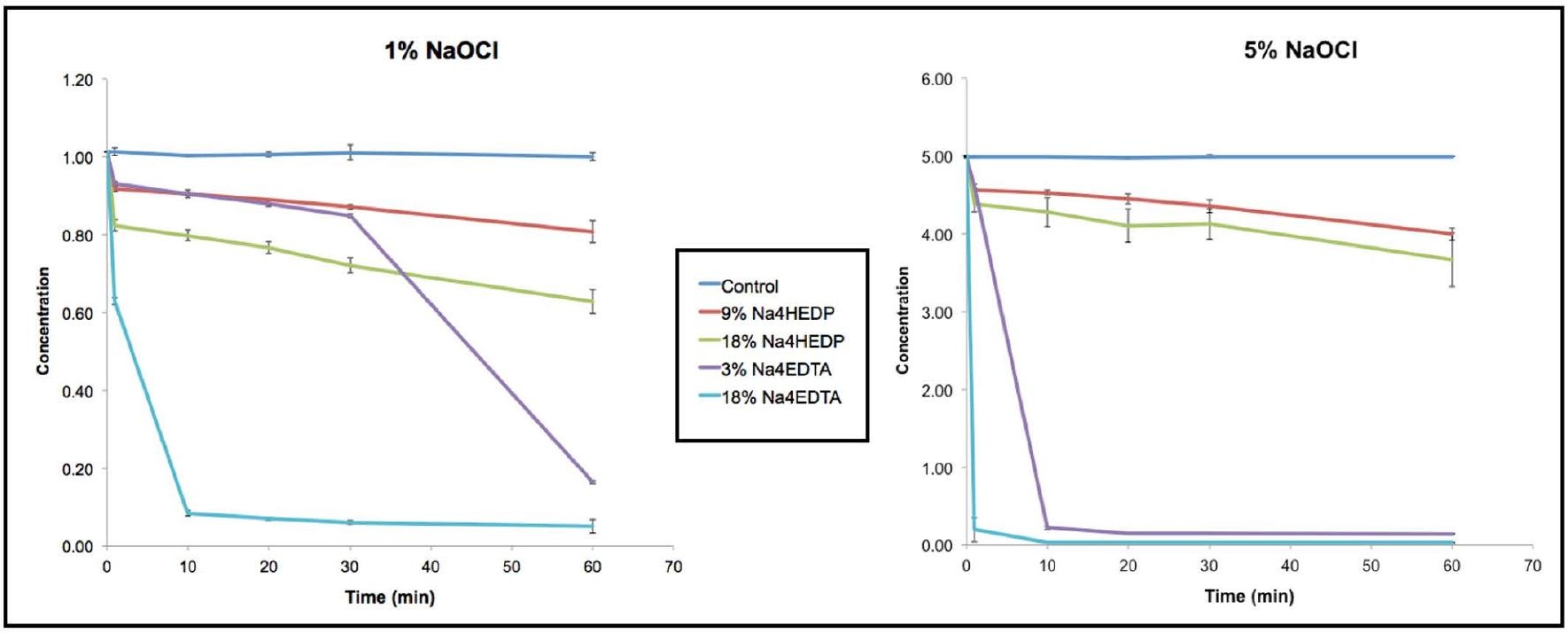


TABLE 1. Available chlorine (\% of theoretical maximum), $\mathrm{pH}$ and temperature $\left({ }^{\circ} \mathrm{C}\right)$ in $10 \mathrm{~mL}$ of a $1.0 \% \mathrm{NaOCl}$ solution in a polypropylene syringe after addition of the chelator salt

\section{Salt (wt/wt) \\ $18 \% \mathrm{Na}_{4} \mathrm{HEDP}$}

Available chlorine

$\mathrm{pH}$ range

Temperature

9\% $\mathrm{Na}_{4} \mathrm{HEDP}$

Available chlorine

$\mathrm{pH}$ range

Temperature

18\% $\mathrm{Na}_{4}$ EDTA

Available chlorine

$\mathrm{pH}$ range

Temperature

3\% $\mathrm{Na}_{4}$ EDTA

Available chlorine

$\mathrm{pH}$ range

Temperature

none (control)

Available chlorine

$\mathrm{pH}$ range

Temperature

\section{$1 \mathrm{~min}$}

20 min
$30 \mathrm{~min}$

$60 \mathrm{~min}$

$\begin{array}{lllll}95 \pm 2 \% & 92 \pm 2 \% & 88 \pm 2 \% & 83 \pm 2 \% & 72 \pm 3 \% \\ 11.6 & 11.5-11.7 & 11.4-11.6 & 11.3-11.5 & 11.1-11.2 \\ 24 \pm 0^{\circ} \mathrm{C} & 24 \pm 0^{\circ} \mathrm{C} & 24 \pm 0^{\circ} \mathrm{C} & 23 \pm 0^{\circ} \mathrm{C} & 23 \pm 0^{\circ} \mathrm{C}\end{array}$

$99 \pm 1 \%$

$97 \pm 0 \% \quad 95 \pm 0 \%$

$93 \pm 1 \%$

$87 \pm 3 \%$

$\begin{array}{lllll}11.0-11.2 & 11.1-11.2 & 11.1 & 11.0-11.1 & 10.9-11.0\end{array}$

$22 \pm 0^{\circ} \mathrm{C} \quad 22 \pm 0^{\circ} \mathrm{C} \quad 22 \pm 0^{\circ} \mathrm{C} \quad 22 \pm 0^{\circ} \mathrm{C} \quad 22 \pm 0^{\circ} \mathrm{C}$

$$
73 \pm 1 \% \quad 10 \pm 1 \%
$$

$8 \pm 0 \%$

$9.7-9.8$

$7 \pm 1 \%$

$9.7-9.8$

$6 \pm 2 \%$

$11.2-11.5 \quad 9.8$

$23 \pm 0{ }^{\circ} \mathrm{C}$

$22 \pm 0{ }^{\circ} \mathrm{C}$

9.7

$21 \pm 1^{\circ} \mathrm{C} \quad 25 \pm 0^{\circ} \mathrm{C}$

$$
95 \pm 1 \%
$$

$$
93 \pm 1 \%
$$

$90 \pm 1 \%$

$87 \pm 1 \%$

$17 \pm 0 \%$

$12.1-12.6 \quad 12.1-12.2 \quad 11.5-12.0$

$20 \pm 1{ }^{\circ} \mathrm{C}$

$21 \pm 0{ }^{\circ} \mathrm{C}$

$21 \pm 0^{\circ} \mathrm{C}$

$21 \pm 0^{\circ} \mathrm{C}$

$9.7-9.8$

$20 \pm 11^{\circ} \mathrm{C}$

$100 \pm 1 \%$

$99 \pm 0 \%$

$100 \pm 1 \%$

$100 \pm 2 \% \quad 99 \pm 1 \%$

11.7

$11.6-11.811 .7$

$22 \pm 1{ }^{\circ} \mathrm{C}$

$22 \pm 0{ }^{\circ} \mathrm{C}$

$22 \pm 0^{\circ} \mathrm{C}$

$11.7-11.8 \quad 11.6-11.8$

$22 \pm 0{ }^{\circ} \mathrm{C} \quad 22 \pm 0{ }^{\circ} \mathrm{C}$ 
TABLE 2. Available chlorine (\% of theoretical maximum), $\mathrm{pH}$ and temperature $\left({ }^{\circ} \mathrm{C}\right)$ in $10 \mathrm{~mL}$ of a $5.0 \% \mathrm{NaOCl}$ solution in a polypropylene syringe after addition of the chelator salt

\section{Salt (wt/wt) \\ $18 \% \mathrm{Na}_{4} \mathrm{HEDP}$}

Available chlorine

$\mathrm{pH}$ range

Temperature

9\% $\mathrm{Na}_{4} \mathrm{HEDP}$

Available chlorine

$\mathrm{pH}$ range

Temperature

18\% $\mathrm{Na}_{4}$ EDTA

Available chlorine

$\mathrm{pH}$ range

Temperature

$3 \% \mathrm{Na}_{4}$ EDTA

Available chlorine

$\mathrm{pH}$ range

Temperature

none (control)

Available chlorine

$\mathrm{pH}$ range

Temperature

\section{$1 \mathrm{~min}$}

\section{0 min}

30 min

$60 \mathrm{~min}$

$\begin{array}{lllll}100 \pm 0 \% & 99 \pm 4 \% & 95 \pm 5 \% & 95 \pm 5 \% & 84 \pm 8 \% \\ 12.3-12.7 & 11.9-12.6 & 12.1-12.3 & 11.9-12.4 & 10.5-11.6 \\ 23 \pm 2^{\circ} \mathrm{C} & 24 \pm 2{ }^{\circ} \mathrm{C} & 24 \pm 2^{\circ} \mathrm{C} & 24 \pm 1^{\circ} \mathrm{C} & 25 \pm 2{ }^{\circ} \mathrm{C}\end{array}$

$98 \pm 1 \%$

12.3

$22 \pm 1^{\circ} \mathrm{C}$

$98 \pm 1 \%$

$96 \pm 1 \%$

$94 \pm 2 \%$

$86 \pm 2 \%$

$11.9-12.311 .5-12.1$

$10.8-11.99 .9-10.4$

$22 \pm 1{ }^{\circ} \mathrm{C}$

$22 \pm 1{ }^{\circ} \mathrm{C}$

$23 \pm 1^{\circ} \mathrm{C}$

$$
\begin{array}{lllll}
5 \pm 4 \% & 1 \pm 0 \% & 1 \pm 0 \% & 1 \pm 0 \% & 1 \pm 0 \% \\
8.8-11.8 & 8.6-8.7 & 8.6-8.7 & 8.6-8.7 & 8.6-8.7 \\
38 \pm 10^{\circ} \mathrm{C} & 33 \pm 2^{\circ} \mathrm{C} & 28 \pm 1^{\circ} \mathrm{C} & 26 \pm 0{ }^{\circ} \mathrm{C} & 22 \pm 0{ }^{\circ} \mathrm{C}
\end{array}
$$

$$
\begin{array}{lllll}
96 \pm 1 \% & 5 \pm 0 \% & 3 \pm 0 \% & 3 \pm 0 \% & 3 \pm 0 \% \\
10.3-10.9 & 7.0-7.5 & 6.9-7.0 & 6.9-7.0 & 6.9-7.0 \\
22 \pm 1^{\circ} \mathrm{C} & 49 \pm 3{ }^{\circ} \mathrm{C} & 37 \pm 1{ }^{\circ} \mathrm{C} & 30 \pm 1{ }^{\circ} \mathrm{C} & 26 \pm 1{ }^{\circ} \mathrm{C}
\end{array}
$$

$$
\begin{array}{lllll}
100 \pm 0 \% & 100 \pm 0 \% & 100 \pm 0 \% & 100 \pm 0 \% & 100 \pm 0 \% \\
12.4-12.5 & 12.4-12.6 & 12.3-12.5 & 12.5-12.7 & 12.5-12.6 \\
22 \pm 0^{\circ} \mathrm{C} & 22 \pm 0^{\circ} \mathrm{C} & 22 \pm 0^{\circ} \mathrm{C} & 22 \pm 0^{\circ} \mathrm{C} & 22 \pm 0^{\circ} \mathrm{C}
\end{array}
$$


TABLE 3. $\mathrm{Ca}^{2+}$ that was chelated (\% reduction) when $0.2 \mathrm{~mL}$ of mixtures of the tetrasodium salts of HEDP or EDTA with deionized water or sodium hypochlorite solutions pre-incubated in $10-\mathrm{mL}$ polypropylene syringes for different time intervals were added to $100 \mathrm{~mL}$ of a $100 \mathrm{ppm}$ calcium chloride standard solution

\begin{tabular}{llll}
\hline Mixture (wt/wt) & Immediately & 30 min & $\mathbf{6 0 ~ m i n}$ \\
\hline $18 \%$ HEDP in water & $82 \pm 1 \%$ & $83 \pm 1 \%$ & $82 \pm 2 \%$ \\
$18 \%$ HEDP in 5\% NaOCl & $75 \pm 1 \%$ & $68 \pm 2 \%$ & $62 \pm 3 \%$ \\
$18 \%$ EDTA in water & $39 \pm 1 \%$ & $40 \pm 3 \%$ & $44 \pm 1 \%$ \\
$18 \%$ EDTA in 5\% NaOCl & $34 \pm 3 \%$ & $30 \pm 4 \%$ & $29 \pm 3 \%$ \\
\hline
\end{tabular}

Triplicate experiments, means and standard deviations. 